\title{
How to deal with the conflicts in public organizations : evidence from China
}

\author{
Yu Baiqing \\ School of Management, Harbin Institute of Technology, Harbin, China, 150001
}

(Email: ybqsds@126.com)

\begin{abstract}
Our paper divides the conflict period to three phases according their characteristics and the law of evolution in the three modes, in order to offer theoretical evidence for conflicts diagnosis and conflicts management; based on the three phases, we discuss the conflict management in Chinese public organizations from the perspective of the leaders in Chinese governments based on the questionnaire survey method. From our empirical result we think it is the first job for the governmental leaders to avoid or eliminate the conflict as soon as possible.
\end{abstract}

Keywords: public conflict, public organization, three phases, questionnaire, China

\section{Introduction}

The conflicts always exist in the public organizations since the conflicts will inevitably when one wants to promote the organization's mission, or to accomplish organizational goals. It is very helpful to play a positive impact on public organizations to reduce the negative effects and promote the healthy development of public organizations if the organization leaders could correctly understand the evolution mechanism of the conflicts and rightly choose the appropriate management strategy to implementation and management of public organizational conflicts.

At present, China has entered a critical period of the nation's urbanization and industrialization, as a result, the social conflicts have raised by the economic restructuring, and the economic conflicts also happened because of stakeholder pluralism. It seems that China has stepped into a more contradictions period since the period when one country's per capita GDP reaches $\$ 3,000$ is regarded as the prominent time of social conflicts. Thus conflict is an ever present reality in modern fast changing China.

In China, some governments did not well deal with public conflict, which led to some small conflict evolved into terrible social conflict events. This kind of serious government conflicts caused enormous negative impacts on these local organizations this is the horrible consequence for ignoring the conflicts and lacking of the rational methods to handle conflicts (Guo, 2006).

Only a few studies have focused on the conflict management in the world. Thomas (1976) constructed the Thomas-Kilman Conflict Management Measurement Scale; Rahim proposed a management list of conflicts in public organization; Renwick invented an Employer Conflicts Measurement Scale (Jameson, 1999). These three measurement scales has been widely accepted by the scholars to empirically examine the conflict management as the main methods.

However, most western theories of organization conflict are often limited to low-level crowd, and the powerful analysis from the leaders' perspective is urgently needed. Meanwhile, there is a lack of empirical researches on public organization conflicts in the Chinese context, and only a few studies focus on the conflict management for public organizations conflict management in Chinasome of the academic points of Chinese scholars also remain in the "discussion" level, without convincing empirical results.

Differing from the previous literatures, this article first discusses the conflict management in Chinese public organizations from the perspective of the leaders in Chinese governments based on the questionnaire survey method. The analysis will be more clear and coherent if we can investigate the conflict 
management issue from a view of leaders, whose finding will give the useful suggestions for the future practice in Chinese governments.

The rest of the article is organized as follows. The conflict in public organizations has been divided into three phases according to their characteristics and time-changing in Section 2. A case study basing on questionnaire from Chinese government officials is reported in Section 3. The paper ends with the conclusions and policy implications for Chinese governments.

\section{Phases of conflict in public organizations}

The paper here will regard the three phases of conflicts as three modes of conflicts and elaborate further on the characteristics and the law of evolution in the three modes, so as to offer theoretical evidence for conflicts diagnosis and conflicts management. The public organization conflict is divided to three phases over time: Potential Conflict Phase, Burgeoning Conflict Phase and Emerging Conflict Phase, as shown in Figure 1.

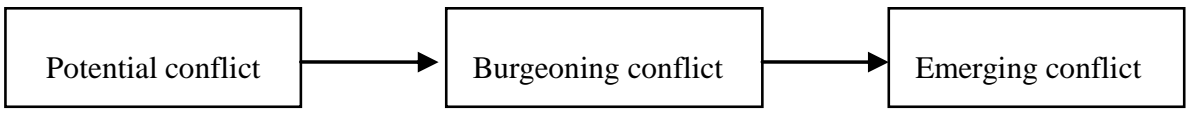

Fig. 1: Conflict Evolution Model

Potential phase of conflict: the main characteristic of conflict in this stage is the invisibility. Only when new conflict components are added or original components grow uncontrollably, complete conflict factors appear. Because these components are incomplete conflict factors, so they do not

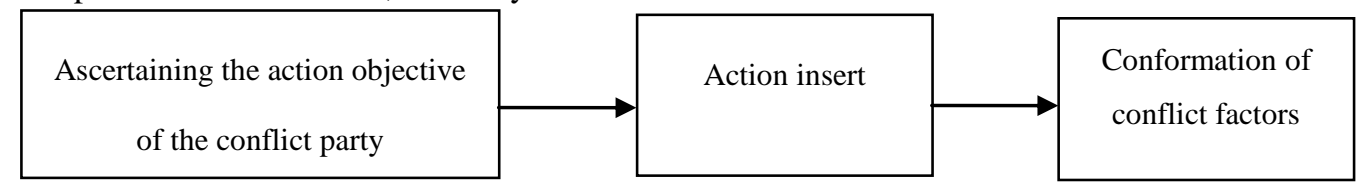

Fig. 2: The Evolution Model Of The Potential Conflict
At the potential phase, the evolution process of the conflict has started, even though the balanced status is not broken yet. The conflict is approaching to the Burgeoning phase.

Burgeoning phase of conflict: during this period, the conflict party is realizing the conflict, not only knowing the existence of conflict content, but also making sure the effects of this conflict for oneself. This type of conflict is in the development towards certain necessarily lead to conflict but still it is a necessary condition for conflicts (Sheppard, 1984). Once components are accumulated or other conditions are added properly, evolution of the conflict kicks off. The evolution procedure is presented in Figure 2.

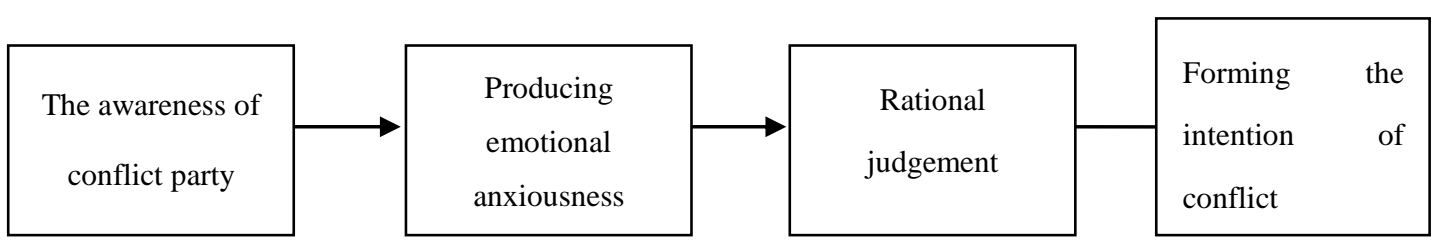

Fig. 3: The Evolution Model Of The Burgeoning Conflict
In this period, the original balance in one system has been broken, and the conflict is on the road of emerging stage.

Emerging stages: in the emerging stage, the conflict has become a reality. Compared full form of conflict. The agents in the passive position are still lack of action, so the situation is still stable and conflict has not completely emerged from the underground. Yet, the conflict is in the touch-and-go state, because the active party and the passive party are in a tense relationship. The time span of this process depends on the agility of the passive party. The evolution model in this period is reported in Figure 3. with the first two phases, the importance of the conflict diagnosis is: What is the cause of the conflict? Which type is this conflict? These answers could

provide the basis for conflict management. Conflict diagnosis is often taken to the 
observation and investigation methods. The difference between these two methods is that the observation work can be finished in the office, but the investigation job based on the questionnaire can only be completed in the middle of the conflict parties, face to face (Thomas, 1976). The evolution model of the emerging conflict can be seen in Figure 4.

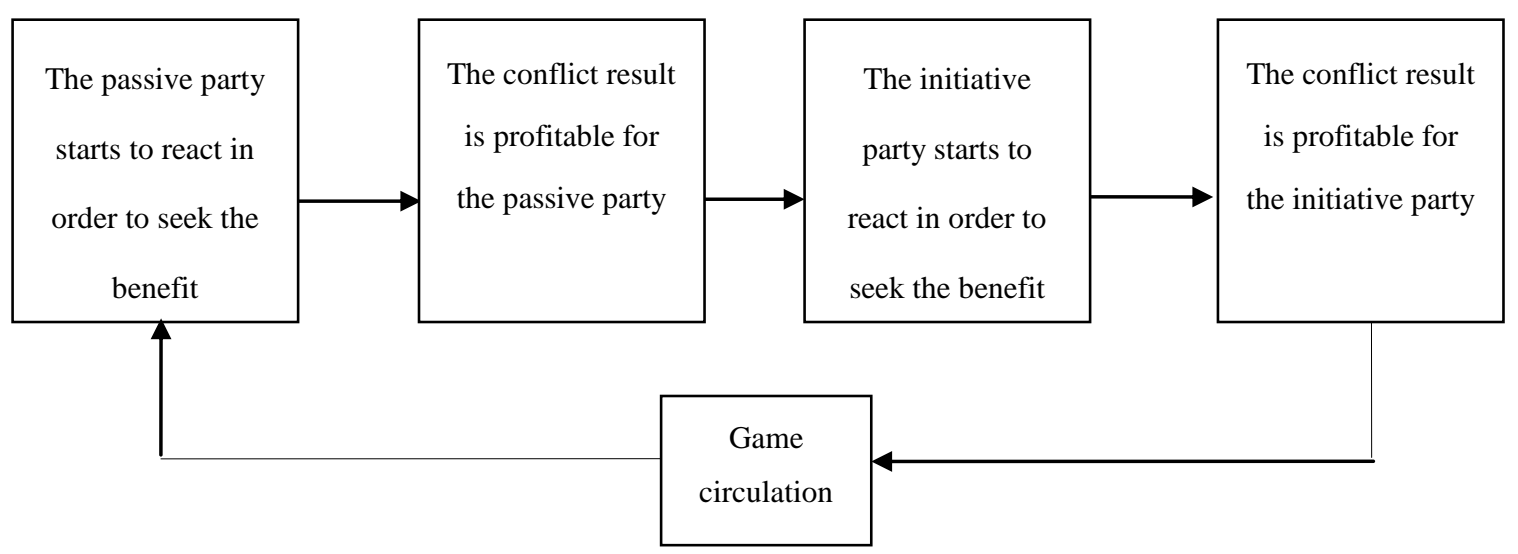

Fig. 4: The Evolution Model of the Emerging Conflict

The destruction effects is becoming bigger and bigger since the two conflict parties have entered into the game circulation. Therefore, the conflict management force should get involved, in order to resolve the conflict by some ways, possible changing the current institution.
The main characterises of conflict in the potential phase, burgeoning phase and emerging phase have been summarized above. Indeed, there also exist interactions between these three phases, mainly by the information transaction, as shown in Figure 5.

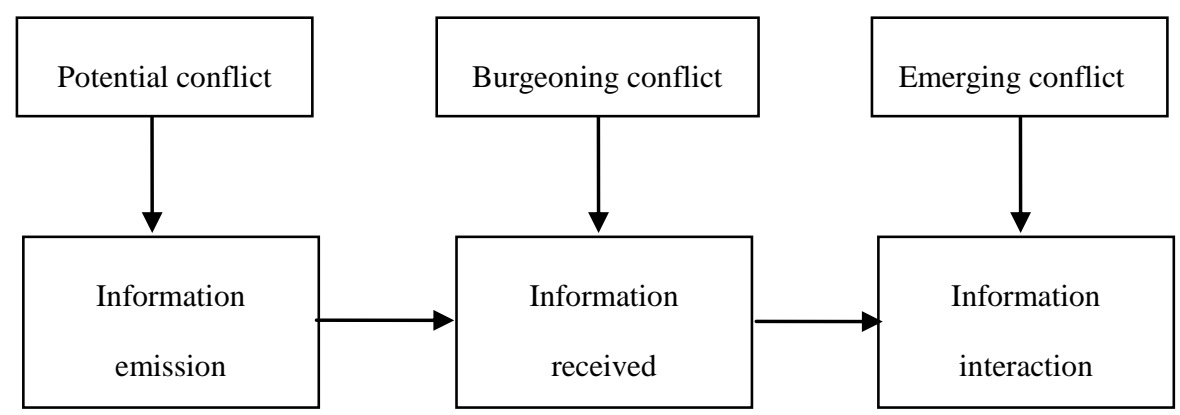

Fig. 5: The interaction between potential, embryonic and emerging conflict

In the potential phase, the initiative party of the conflict is very active, sending the conflict information to the passive conflict party. In the burgeoning phase, the passive party has received the conflict information and starts to receive conflict message and then recognizes and perceives these messages (Pondy, 1967). In the emerging phase, both sides are engaged in active thinking. They exchange messages and participate in conflicts. With these relationships at hand, through the analysis of fundamental characteristics, evolution mechanism, evolution process and results in the different stages of organizational conflicts, conflict managers know what the major conflict is about and where this conflict lies and how to make conflict-managing strategies that fit with principles and rules of conflicts, so as to make correct diagnosis and decisions of managing organization conflicts.

\section{Case study based on questionnaire from Chinese government officials}

Empirical study is employed in this research. Based on the conflict theories established by both domestic and aboard scholars, and taking into account the features of public organizations in China, the questionnaire was 
designed in Likert Scale questions and questions with one answer to each. This was to find out how well the organization leaders diagnosis and handle the conflicts in current China. The survey of public organizational conflicts in China was conducted in April, 2012 by circulating the questionnaire among the public organizations in five provinces in three areas - central, eastern and western China, and one metropolis. Then the statistics drawn from the valid responses were analyzed by employing SPSS 20. Four hundred copies of the questionnaire were distributed to local party committees, people's congresses, governments, political consultative conferences, non-government organizations, public security bureaus, people's procuratorates, people's courts and 4 non-public organizations who were very supportive and cooperative. Three hundred and eighty five copies were collected and 364 were valid with validity rate of $94.5 \%$.

\subsection{Design of the Questionnaire}

The questionnaire was designed to analyze and measure property of the survey. In order to meet the purposes of the survey, the principles established by Li Huaizu (2004) and other scholars were mainly observed. These include:
A. In terms of the content of the questionnaire, all the questions must be closely related to what the survey aimed at, avoiding questions with tendentiousness and inductiveness so that no hints were given.

B. In terms of wording, all questions were written in a simple and plain style, avoiding stiff, hard-to-understand technical terms so the subjects would fully and accurately understand everything in the questionnaire.

C. In terms of sequence, questions about the aim of the survey should be put at the beginning so that the subjects are sure that all the information will be handled for the purpose of the survey only without any leaking of information for other purposes, and then questions with the same theme are grouped together.

\subsection{Empirical findings based on the}

\section{Questionnaire}

The data collected from the questionnaire was processed by SPSS. We re-organized the chosen conflict management methods in sequence, and the empirical results are reported in Table 1.

\begin{tabular}{|c|c|c|c|c|c|}
\hline Questions & Methods & Min-value & Max-value & Mean & $\begin{array}{l}\text { Standard } \\
\text { Deviation }\end{array}$ \\
\hline \multirow{4}{*}{$\begin{array}{l}\text { What methods will you } \\
\text { choose when you deal } \\
\text { with the conflict in the } \\
\text { potential phase? }\end{array}$} & $\begin{array}{l}\text { Eliminate the producing } \\
\text { conflict factors }\end{array}$ & 1 & 5 & 4.3187 & 0.7908 \\
\hline & $\begin{array}{l}\text { Construct the same worth } \\
\text { sense }\end{array}$ & 1 & 5 & 4.1978 & 0.8524 \\
\hline & $\begin{array}{l}\text { Create the balance between } \\
\text { benefit and cost }\end{array}$ & 1 & 5 & 4.1016 & 0.8957 \\
\hline & Other methods & 1 & 5 & 3.6648 & 0.9047 \\
\hline \multirow{5}{*}{$\begin{array}{l}\text { What methods will you } \\
\text { choose when you deal } \\
\text { with the conflict in the } \\
\text { burgeoning phase? }\end{array}$} & $\begin{array}{l}\text { Change the conflict to the } \\
\text { positive factor }\end{array}$ & 1 & 5 & 4.1896 & 0.9120 \\
\hline & $\begin{array}{l}\text { Change the conflict parties' } \\
\text { recognition }\end{array}$ & 1 & 5 & 4.1538 & 0.8742 \\
\hline & $\begin{array}{l}\text { Postpone the time of } \\
\text { conflict produce }\end{array}$ & 1 & 5 & 3.5934 & 1.1640 \\
\hline & $\begin{array}{l}\text { Change the place of } \\
\text { conflict produce }\end{array}$ & 1 & 5 & 3.4670 & 1.1767 \\
\hline & $\begin{array}{l}\text { Change the roles of the } \\
\text { conflict parties }\end{array}$ & 1 & 5 & 3.5385 & 1.1905 \\
\hline
\end{tabular}




\begin{tabular}{|c|c|c|c|c|c|}
\hline & Other methods & 1 & 5 & 3.5110 & 0.8798 \\
\hline \multirow{11}{*}{$\begin{array}{l}\text { What methods will you } \\
\text { choose when you deal } \\
\text { with the conflict in the } \\
\text { emerging phase? }\end{array}$} & $\begin{array}{l}\text { Persuade the conflict } \\
\text { parties }\end{array}$ & 1 & 5 & 4.4423 & 0.7638 \\
\hline & $\begin{array}{l}\text { Positive solution to the } \\
\text { problem }\end{array}$ & 1 & 5 & 4.1786 & 0.8121 \\
\hline & Wait for some time & 1 & 5 & 3.8462 & 1.0568 \\
\hline & $\begin{array}{l}\text { Solve the conflict after } \\
\text { Clear the periphery }\end{array}$ & 1 & 5 & 3.8324 & 0.9575 \\
\hline & $\begin{array}{l}\text { Cut the interests groups } \\
\text { into a plurality of groups }\end{array}$ & 1 & 5 & 3.6758 & 1.1056 \\
\hline & Transfer Conflict View & 1 & 5 & 3.6648 & 1.0616 \\
\hline & $\begin{array}{l}\text { Punish the key person in } \\
\text { the conflict }\end{array}$ & 1 & 5 & 3.5357 & 1.1239 \\
\hline & $\begin{array}{l}\text { Process the conflict } \\
\text { according to the } \\
\text { organization }\end{array}$ & 1 & 5 & 3.3132 & 1.2622 \\
\hline & $\begin{array}{l}\text { Resolve the conflict by new } \\
\text { conflict }\end{array}$ & 1 & 5 & 3.2967 & 1.2705 \\
\hline & $\begin{array}{l}\text { Compromise to the conflict } \\
\text { parties }\end{array}$ & 1 & 5 & 3.0824 & 1.2526 \\
\hline & Other methods & 1 & 5 & 3.4890 & 0.9285 \\
\hline \multirow{4}{*}{$\begin{array}{l}\text { What methods will you } \\
\text { choose when you deal } \\
\text { with the actually occurred } \\
\text { conflict } \\
\text { ? }\end{array}$} & $\begin{array}{l}\text { The mediation, arbitration } \\
\text { or administrative litigation }\end{array}$ & 1 & 5 & 4.1786 & 0.9321 \\
\hline & Negotiation resolution & 1 & 5 & 4.1016 & 0.8895 \\
\hline & Force resolution & 1 & 5 & 2.2830 & 1.4063 \\
\hline & Other methods & 1 & 5 & 3.3874 & 0.9336 \\
\hline \multirow{6}{*}{$\begin{array}{l}\text { The controlled factors of } \\
\text { organization conflict } \\
\text { include: }\end{array}$} & Solutions of the conflict & 1 & 5 & 4.0467 & 0.8269 \\
\hline & Frequency of the conflict & 1 & 5 & 4.0247 & 0.8732 \\
\hline & $\begin{array}{l}\text { Intense degree of the } \\
\text { conflict }\end{array}$ & 1 & 5 & 4.0082 & 0.9520 \\
\hline & Procedure of the conflict & 1 & 5 & 3.8929 & 0.9073 \\
\hline & Result of the conflict & 1 & 5 & 3.8681 & 0.9501 \\
\hline & Root of the conflict & 1 & 5 & 3.6841 & 1.1363 \\
\hline \multirow{5}{*}{$\begin{array}{l}\text { The main actions to } \\
\text { express the organization } \\
\text { conflict include: }\end{array}$} & Psychological conflict & 1 & 5 & 4.2060 & 0.8521 \\
\hline & Uncooperative work & 1 & 5 & 4.0357 & 0.9883 \\
\hline & Reflect to the leaders & 1 & 5 & 4.0220 & 0.8935 \\
\hline & Murmur in private & 1 & 5 & 3.9945 & 0.8751 \\
\hline & Argue in public & 1 & 5 & 3.8984 & 1.0058 \\
\hline
\end{tabular}


Table 1: The Chosen Methods Of Conflict Management In Different Phases

From the statistical results, we can see that in the potential phase of conflict in public organization, most the leaders chose to eliminate the conflict factors, which already happen in the organization. That fact indicates in Chinese governments, all the leaders tried to avoid the conflict and did their utmost to recognize the potential conflict in order to head off a conflict event. In the burgeoning phase, obviously the leaders preferred to change the conflict parties at first time, and they believed that it was not very useful if they postponed the conflict or changed another place for the conflict. In the emerging phase, the leaders still wanted to deal with the conflict first from persuading the conflict parties, and most of them chose face the conflict directly. A large proportion of the total leaders chose to resolve the conflict by mediation and negotiation. At the same time, the leaders believed that the solution, frequency and intense degree of the conflict were the main controlled factors of organization conflict, and the main action to express the organization conflict is Psychological conflict.

\section{Conclusions}

Our paper divides the conflict period to three phases according their characteristics and the law of evolution in the three modes, in order to offer theoretical evidence for conflicts diagnosis and conflicts management; based on the three phases, we discuss the conflict management in Chinese public organizations from the perspective of the leaders in Chinese governments based on the questionnaire survey method. From our empirical result we think it is the first job for the governmental leaders to avoid or eliminate the conflict as soon as possible. Thus, in the potential phase, most the leaders chose to eliminate the conflict factors, which already happen in the organization; in the burgeoning phase, the leaders preferred to change the conflict parties at first time; in the emerging phase, the leaders still wanted to deal with the conflict first from persuading the conflict parties, and most of them chose face the conflict directly.

\section{References}

Guo, F., \& Shi, S. M.,On conflict management in public organizations. Journal of Liaoning Administration College, Vol. 4.,2006(in

Chinese).

[1] Han, P..Harmonious conflict management within administrative organizations. Journal of Suzhou University. Suzhou University Press.,2006(in Chinese).

[2] Jameson, J.K. Toward a Comprehensive Model for the Assessment and Management of Intraorganizational Conflict: Developing the Framework [J]. The International Journal of Conflict Management, 1999, 10 (3): 268-294.

[3] Liu, X.. Analysis of conflicts and management within public organizations in China. Unpublished master's thesis obtained from Northeast Normal University.,2008(in Chinese).

[4] Pan, X. J..Reflection on administrative organizational conflict management in China, Unpublished master's thesis obtained from Sichuan Normal University.,2007(in Chinese).

[5] Pondy, L. R.. Organizational conflict: concepts and models. Administrative Science Quarterly ,1967:(296-320).

[6] Sheppard, B. H. Third party conflict intervention: A Procedural Framework, In B. M. Staw \& L. L. Cummings (Eds.), Research in Organizational Behavior [C], 1984, 6: 141-190.

[7] Thomas, K. W.. Conflict and conflict management. In M. D. Dunnette \& L. M. Hough (Eds.). Handbook of Industrial and Organizational Psychology, Palo Alto: Consulting Psychologists Press, 1976:889-935 